\title{
Health and safety of students in vocational training in Quebec: a gender issue?
}

\author{
Céline Chatigny, Jessica Riel and Livann Nadon \\ Interdisciplinary Centre for the Study of Biology, Health, Society and the Environment (CINBIOSE). Universite du \\ Québec à Montréal (UQAM), DÉFS, C.P. 8888. Succ. Centre-ville, Montréal (Québec), Canada, H3C 3P8.
}

\begin{abstract}
Health and safety issues in a vocational training center were explored in this study. Several sources and methods were used: group interviews with students in traditionally female $[\mathrm{F}]$ and male $[\mathrm{M}]$ trades, i.e. hairdressing $(7 \mathrm{~F})$ and automated systems electromechanics $(8 \mathrm{M}, 1 \mathrm{~F})$; self-administered questionnaires on injuries sustained at the school; observations of activities in these programs; and analysis of ministerial documents. Findings indicate that the partially divergent ways that OHS is addressed in these programs cannot be explained only by the specific characteristics of the two trades. Some aspects put female students in hairdressing at a disadvantage: status accorded to OHS in the study programs, learning activities, and conditions for learning and managing prevention and injuries. The discussion focuses on a genderdifferentiated analysis, the importance of improving the way OHS is addressed in the programs, in particular, those primarily involving female students, and the need to pursue research. In addition, the results from individual interviews with women (5 F) training for non-traditional trades lead to discussion on the interrelated effects of sex-based gender and professional gender.
\end{abstract}

Keywords: Gender, occupational health and safety, vocational training, students, ergonomics

\section{Problem}

In vocational training centres (VTCs), teachers as well as students may be exposed to various risks due to the activity they perform $[27,33]$. A great number of activities are in fact carried out in workshops, where there are equipment, tools, materials, and, in some cases, clients. The teaching and learning of Occupational Health and Safety (OHS) practices are thus important and the ministère de l'Éducation, du Loisir et du Sport (MELS, Quebec Ministry of Education) stipulates some aspects of it in the study programs. Moreover, the Commission de la santé et de la sécurité au travail (CSST, Quebec's worker compensation board) has been highly present in VTCs since the Protocol of Quebec [2], which aims to integrate OHS practices into vocational and technical training because, in particular, of a high rate of injuries among young people [9,24]. *

* Corresponding author. Email: chatigny.celine@uqam.ca
The gender issue immediately came up for the researchers and union partners involved in this ergonomic study. The exploration of occupational health and safety issues in VTCs should include a gender-differentiated analysis, given that men and women's work-related health is affected differently. Workplace studies have in fact made it possible to examine the relationship between gender and OHS practices. Men and women are distributed in different occupations, and in mixed gender workplaces, work is often assigned according to gender because of the sexual division of labour. They are thus exposed to risks and impacts that are partly different $[1,17,18]$. Men are more often victims of accidents; women are more severely affected by musculoskeletal disorders $[13,28]$. In the context of traditionally male jobs ${ }^{1}$ many women are exposed to discrimination, harassment and exclusion $[4,11,19]$. In the service

1 "Traditionally male trades and occupations refer to activity areas in which women represent less than $331 / 3$ percent. This is referred to as under-representation." 1 
sectors, where women represent the majority, constrained postures, the accumulation of tasks, and sources of violence affect these workers' physical and mental health and their work-family balance $[14,15]$. Often perceived to be easier because they are associated with skills presumed to be intrinsically female, the cognitive, emotional and physical demands of their work are underestimated [5,8,26].

In Quebec, job sectors are classified, for OHS risk prevention purposes, into six industries. Three of these, recognized as priority sectors because of the severity of accidents, include jobs in the primary and secondary industries, mainly male-dominated and partly mixed. The other sectors, which include jobs in the secondary and service industries and which are mainly mixed and female-dominated, are not obliged by law to have health and safety committees or a safety representative. This situation reflects a vision of OHS which overlooks the risks of progressive deterioration in health. Moreover, although the law (LSST) establishes shared responsibility between employers and workers, the culture of prevention in many workplaces (small and medium-sized businesses) mainly targets individual responsibility. Consequently, few training programs offer tools to identify and prevent risks in order to develop efficient know-how about risk avoidance [3, 31,32], essential to achieve production goals while protecting workers' health (for example, pairing up with a coworker when moving a patient in order to ease the physical demands of the task).

All this knowledge provided guidance for the analysis of OHS. The results presented here involve students enrolled in traditionally female- and maledominated programs.

\section{Methods and population}

The approach was the ergonomic analysis of work activity $[24,10]$. Representations for action, learning situations and organizational determinants were at the centre of the analysis [7]. This approach was based on action-research with the participation of follow-up committees; one within the VTC, the other made up of social partners in education and OHS. Documents from the partner organizations were examined. Particular attention was devoted to aspects of OHS in two ministerial documents: Analyse de la situation de travail (Analysis of the Work Situation, AWS) [20,21] and Programme d'études (Study Programs) [22,23]. Statements were listed and categorized so as to identify the types of learning that are likely to be linked to OHS. The project was accepted by the ethics committee (comité de déontologie) of the Université du Québec à Montréal, and consent forms were provided to participants.

The VTC is large (146 teachers: $58 \mathrm{~F}, 88 \mathrm{M}$; accommodating up to 1500 students) and is located in the outskirts of a city. Twenty-four (24) full-time programs are offered there. It was chosen based on the interest in developing OHS on the part of the school administration, the union and teachers, study programs that varied in terms of OHS, male-female student representation and diversity among the teachers (sex, age, seniority, job status).

Several methods and data sources were triangulated. The interviews used for this article were conducted with 21 volunteer participants: 19 students (11 F, $8 \mathrm{M}$ ) from four programs (Hairdressing hereafter HD, Automated Systems Electromechanics - hereafter ASE, Fitting and Welding, Building Drawing) and 2 female teachers (one in training) in non-traditional trades (Refrigeration, Automotive Mechanics). The interviews focused on the participants' educational path, their representation of OHS in relation to the trade and the learning of OHS practices. During group interviews, the participants each filled out a questionnaire on the risks they faced at school and the effects on their health. Data collection documents were designed based on preliminary research conducted in another VTC [6] and were validated with students in other schools. The analytical categories were created gradually, using predefined themes (including students' representations of OHS, injuries sustained in the training centre and conditions for learning) as well as the gathered data [29]. Gender-differentiated analysis was used to shed light on the OHS of the participating men and women [16].The high-school level vocational training sector in Quebec teaches 150 trades. Teachers are first of all experts in their trade who subsequently choose to teach. The malefemale representation (all programs combined) is $58.8 \% \mathrm{M}$ and $41.2 \% \mathrm{~F}$ for teachers, and $56.4 \% \mathrm{M}$ and $43.6 \% \mathrm{~F}$ [30] for students. Table 1 presents the age and sex characteristics of students participating based on their study program and the male-female representation in Quebec in these programs. It can be observed that these programs are almost completely female- or male-dominated. Students of the opposite sex are in the very small minority, which increases the risk of marginalization. 
Table 1

\begin{tabular}{|c|c|c|c|c|}
\hline Study programs & \multicolumn{2}{|c|}{$\begin{array}{l}\text { M-F representation in the program in Quebec } \\
1 \text { (Gouvernement du Québec, 2008) [12]; } 2 \text { (Ouellette, 2008) [30] }\end{array}$} & \multicolumn{2}{|c|}{ Sex and age of 21 participants } \\
\hline \multicolumn{5}{|l|}{ STUDENTS } \\
\hline Hairdressing & Traditionally female & $97.2 \% \mathrm{~F} ; 2.8 \mathrm{M}^{1}$ & $7 \mathrm{~F}$ & 18 years old $(18-20)$ \\
\hline $\begin{array}{l}\text { Automated Systems } \\
\text { Electromechanics }\end{array}$ & \multirow[t]{3}{*}{ Traditionally male } & $95.6 \% \mathrm{M} ; 4.4 \mathrm{~F}^{1}$ & $\begin{array}{l}8 \mathrm{M} \\
1 \mathrm{~F}\end{array}$ & 26 years old $(20-42)$ \\
\hline Fitting-Welding & & $92.5 \% \mathrm{M} ; 7.5 \% \mathrm{~F}^{1}$ & $2 \mathrm{~F}$ & 20 and 25 years old \\
\hline Building Drawing & & $90.0 \% \mathrm{M} ; 10.0 \% \mathrm{~F}$ (Building and Public Works Sector) ${ }^{2}$ & $1 \mathrm{~F}$ & 22 years old \\
\hline \multicolumn{5}{|c|}{ OTHERS : female teacher, female teacher-in-training (ex-students) } \\
\hline Refrigeration & \multirow[t]{2}{*}{ Traditionally male } & $90.0 \% \mathrm{M} ; 10.0 \% \mathrm{~F}$ (Building and Public Works Sector) ${ }^{2}$ & $1 \mathrm{~F}$ & 35 years old \\
\hline Automotive Mechanics & & $95.6 \% \mathrm{M} ; 4.4 \% \mathrm{~F}^{1}$ & $1 \mathrm{~F}$ & 27 years old \\
\hline
\end{tabular}

\section{Findings}

The first section below involves aspects of OHS found in the ministerial documents relating to the hairdressing (HD) and automated systems electromechanics (ASE) programs. Other sections derive from the analysis in the training center. Three aspects are presented: the representation of risks among students in these two programs, their experience of OHS risks at school, and some elements of OHS in traditionally-male contexts.

\subsection{OHS in ministerial documents}

Two Ministry of Education documents, Analysis of the Work Situation (AWS) and Study Programs, were analyzed. The AWS is used to design programs based on a list of competencies, each associated with a training module. Teachers must teach these competencies to their students. A first comparison revealed a different match, in each of the two trades analyzed, between the number of tasks and the corresponding number of competencies (Table 2).

The various aspects of OHS vary between HD and ASE since the tasks, requirements and risks associated with these trades differ. The approach to OHS in these programs also differs in some ways.

In $\mathrm{HD}$, as in ASE, the description of the trade refers first to stressful work contexts (HD: clientele; ASE: production stoppages, pressure from supervisors, long working hours, difficult decisions, firms not interested in OHS). These aspects do not figure in the OHS section of the document but rather as psychological skills to be developed (in HD).
Table 2.

Match in terms of number of tasks, competencies and hours in the two trades analyzed in the ministerial documents.

\begin{tabular}{|l|l|l|}
\hline Documents & HD & ASE \\
\hline $\begin{array}{l}\text { Analysis of the } \\
\text { Work Situation }\end{array}$ & 17 tasks & 13 tasks \\
\hline $\begin{array}{l}\text { Study } \\
\text { Programs }\end{array}$ & $\begin{array}{l}\text { 1455 hours } \\
\text { 21 competencies, } \\
\text { including 1 related } \\
\text { to OHS }\end{array}$ & $\begin{array}{l}\text { 1800 hours } \\
\text { including 1 related } \\
\text { to OHS }\end{array}$ \\
\hline
\end{tabular}

In $\mathrm{HD}$, the risks identified are related to posture and chemical products. They never figure in the operations to be carried out or in the conditions in which the operations are carried out. They are considered in terms of the performance to be developed in compliance with a set of rules, in particular, with regard to tasks (4/17) that require the use of chemical products (straightening, coloring, bleaching, and putting highlights in hair). This way of addressing OHS does not take into account the complexity of know-how about risk avoidance and does not lead to actions involving prevention at source. Thus, it is not surprising that the idea of reducing the number of hours of OHS instruction is raised. The OHS appendix (produced by a CSST staff member) presents risks and legislative measures (not all complied with in this sector): fire, electricity, ventilation, layout, posture, equipment, tools, chemical products, work methods.

In ASE, regulations dominate in almost all tasks (11/13) (e.g., Quebec Electrical Code, Act respecting occupational health and safety, sector-specific standards, e.g., food). As in HD, the statements refer to behavioural guidance. According to this approach, following instructions and being disciplined and prudent are expected to make the risks "manageable" (hazardous products, work at height or in a confined 
space, noise, smells, heat, etc.): “[...] Safety at work is always the worker's responsibility" (p.5). This statement contradicts the law which imposes a shared responsibility between the employer and the worker. However, in ASE, a new aspect emerges involving taking action on risks.

In the study programs, one competency (30-hour module) relates to OHS. It is considered in terms of knowledge aimed at the individual application of rules (which is consistent with the AWS).

In ASE, adopting safe behaviors and learning about tools and materials dominated. The contents are pre-established by a joint sector-based association for OHS - construction sector) and approved by the CSST. They set standards and, in addition, introduce actions for managing OHS, such as "drawing up a list of risks related to building sites and preventive measures, defining objectives and the means of preserving the health, safety and physical integrity of the worker and others [...]"'(p.20) [23].

In HD, unlike in ASE, no learning involved preventive interventions at source, and no indications were given to the teachers with regard to establishing conditions for safe supervision. Learning is related to developing work techniques, and organizing their own time and space. This approach is translate into rules of hygiene, of safety, and of hairdressing (e.g., application of means to prevent dermatosis and safe conduct of skin tests [on the client]). Although there may be a link between the hairdresser's safety and that of the client, the client's safety is considered to be an aspect of OHS. This shift in meaning also appears in other modules and introduces confusion concerning the target of OHS, that is, the worker.

\subsection{The students' representation of OHS risks}

During the group interview, the students put forward a definition of OHS and identified what they had retained about OHS from their training. Different trends were identified in the two groups of students.

The HD students defined OHS in terms of protecting the client first, and then protecting themselves. "In our trade, it's really important to protect the client, and also ourselves." Thus, the confusion between the health and safety of the worker and that of the client, identified in the ministerial document referred to above, was also evident in these students' comments. The problems caused by their constrained postures, to which they later referred a great deal, were not mentioned here at all. On the other hand, what stood out most from their training was the importance of good posture: "The teachers talk about it all the time: "Remember to protect your back and shoulders and don't forget to stretch." The students, however, expressed reservations about these measures recommended by their teachers. They did indeed recognize the importance of good posture, but they questioned the effectiveness of stretching: "When your body's already a wreck, stretching doesn't help much." Their dread of musculoskeletal pain was thus accompanied by a sense of resignation (as seen below, many of them were already affected by such pain): "The longer you work, the weaker your body gets. When I see them [hairdressers] standing on the job like that for 5 or 6 hours without a break [...]I'm going to have to put up with that too since I'm not cut out for office work." The students had also retained from their course the importance of keeping their work station clean (e.g., disinfecting the brushes and the chair's footrest between clients) but wondered how realistic this expectation was given the limited time available. They also referred to the risks associated with the chemical products they would be using but they did not mention any preventive measures related to them. These students never mentioned factors such as the stress of dealing with clients, the lack of breaks or the long working hours which are all characteristic of working conditions in hairdressing salons.

The comments of the ASE students $(\mathrm{N}=9)$ revealed a difference in their representation of OHS compared to that of the HD students: they referred to the responsibility of both the firm (employer, productivity, organization, training) and the worker (skills, attitudes). Nevertheless, what they had retained from their training was a focus on individual responsibility: respecting rules, wearing safety equipment, being careful). On the other hand, they also mentioned the following factors affecting working conditions, the decisions made on the job, and the health of workers: being under pressure to produce ("It's often when you're trying to hurry that an accident happens," "When the machine's not running, the company's losing money, and down time is kept track of too," "You want to go faster so you disregard protective measures, you just bypass them"; productivity management ("The more we try to produce, the more OHS is affected"); long hours ("The working conditions on Saturdays and Sundays are exhausting"); and problems with access to equipment. Moreover, these students identified various measures that can minimize OHS risks: 
information and training regarding the dangers presented by the machines, using the right equipment and proper techniques, and not being over-confident. Some students were concerned that the conditions at school did not reflect those in workplaces, and they worried that their teachers were underestimating how poor the working conditions and OHS practices would actually be once they got out there: "We have a top-of-the-line ventilation system here [...] but when you work in a small shop, the only ventilation you get is by opening the garage door. There's always smoke in the air and, of course, we breathe it in." "They'd have us believe that [wearing safety glasses and lock-out $\left.{ }^{2}\right]$ are current practices even though they aren't really." "They don't tell us [...] that our bosses won't give a damn." "Companies don't care about that, their mentality doesn't make room for OHS." "You do what you can." Not all the students, however, were resigned in this way. One male student said, "You have to impose OHS," indicating that he believed he might have the power to do so, an attitude that was not found among the girls in HD.

\subsection{OHS risks at school}

OHS risks are first encountered at school, in the workshops. We compared the conditions in the learning environments and their impacts on the health of the students. Here again, differences were observed between the two programs.

Half of the facilities in HD had not been renovated and were described by the teachers as being unsanitary, and by the students as being inferior to those in real hairdressing salons. Observations revealed several problems: lack of space; inadequate work stations and equipment, which were in poor condition and not well adapted to the height or size of the students (chairs, sinks, tool trolleys, counters, hairdryers, curling irons, wig blocks, brushes and scissors); and the strong smell of hair coloring products, indicating poor ventilation. The teachers said they were tired of fighting and getting so little. During a group interview with teachers from the other programs, the teacher representing $\mathrm{HD}$, who came to realize that requests from ASE were getting a better response from the school administration, exclaimed, "Is it because we don't bang our fists on the table that we don't get anything?"

2 A procedure which involves using a padlock to keep a switch in the "off" position to ensure that hazardous energy sources are kept under control during operations such as maintenance.
Table 4

Accidents involving injuries among students, recorded in the accident registry.

\begin{tabular}{|l|l|}
\hline Departments & $\begin{array}{l}\text { Type of injury and number of students } \\
\text { injured }\end{array}$ \\
\hline \hline $\begin{array}{l}\text { Automated } \\
\text { Systems Electro- } \\
\text { mechanics (ASE) }\end{array}$ & $\begin{array}{l}\text { Cuts to the arm by metal parts or to the head } \\
\text { by stationary equipment (2), cuts to the back } \\
(1), \text { finger sprained by a hand tool (1) }\end{array}$ \\
\hline $\begin{array}{l}\text { Fitting and } \\
\text { Welding }\end{array}$ & $\begin{array}{l}\text { Fingers and hand crushed by stationary } \\
\text { equipment or machinery(3), cuts to the } \\
\text { fingers and eyes by stationary equipment (2) }\end{array}$ \\
\hline $\begin{array}{l}\text { Carpentry and } \\
\text { Joinery }\end{array}$ & Cuts caused by a hand tool (1) \\
\hline Electricity & Crushed finger (1) \\
\hline Refrigeration & Abrasions to the buttocks (1) \\
\hline Machining & Finger cut by a hand tool (1) \\
\hline
\end{tabular}

Table 5

Injuries and pain caused by the learning activities, reported by the students in the two programs.

\begin{tabular}{|l|l|l|}
\hline $\begin{array}{l}\text { Body } \\
\text { areas }\end{array}$ & $\begin{array}{l}\text { Students in HD (N=7) } \\
\text { (no injuries or pain } \\
\text { recorded in registry) }\end{array}$ & $\begin{array}{l}\text { Students in ASE (N=9) } \\
\text { (some injuries recorded } \\
\text { in registry) }\end{array}$ \\
\hline \hline $\begin{array}{l}\text { Inju- } \\
\text { ries }\end{array}$ & $\begin{array}{l}\text { 6 students: back (4), } \\
\text { shoulder (1), neck (1), } \\
\text { hands (1), lower limbs (1), } \\
\text { knee (1) }\end{array}$ & $\begin{array}{l}\text { 6 students: back (4), } \\
\text { elbow (2), hands (2), } \\
\text { knees (3) }\end{array}$ \\
\hline Pain & $\begin{array}{l}5 \text { students: back (3), neck } \\
(1), \text { head (1), arm (1), wrist } \\
(1), \text { hands (3), lower limbs } \\
(1), \text { knees (2) }\end{array}$ & None \\
\end{tabular}

In the ASE department, the machines and equipment were similar to those used in large firms. Observations revealed a large workshop that was well-lit, well-ventilated, clean and uncluttered, and included enough floor space to move freely around the room. Significant investments had been made to reduce OHS risks (electricity, dust, falls, cuts). Several violation notices had been issued by the CSST following inspections and reported accidents.

In 2008-09, all the accidents recorded in the "accident registry" took place in the traditionally male-dominated departments (Table 4). These cases were acted on and followed up on by the school administration. There was no official record in the VTC', of the incidents or pain that can indicate a deterioration in the facilities or in health. There was therefore no record of musculoskeletal problems among the teachers or students.

However, interviews with study participants revealed that the students in both groups sustained injuries or were affected by pain associated with workshop activities, in particular (proportionally 
speaking), the girls in HD: 6 (out of 7) HD students, 14 body areas affected; 6 (out of 9) ASE students, 13 body areas affected. Most of the HD students sustained musculoskeletal injuries or experienced pain that was associated with their learning activities (Table 5). Three students were able to identify the exact activities that had caused the injury or pain through repetitive movements (e.g., using scissors). "It's hard on the body, I'm just starting out, I'm still studying and I already have a sore arm, and especially sore legs. And I haven't even started working yet, I'm still at school." It is not known, at this stage, whether such pain goes away as the students adapt to the work, but these cases raise concerns because: 1) the problems that the students reported corresponded to the body areas in which the teachers also experienced pain [6] associated with their previous work in the trade; one teacher said: "all the students have back pain"; 2) the conditions in the school's hairdressing salon resembled those in real hairdressing salons: providing service to clients, working long hours on their feet with their hands raised, repetitive movements, and equipment that could not easily be adjusted; 3) the burden of prevention rests on the workers since their training does not prepare them to take action to change these conditions. The hairdressing sector is neither unionized nor subject to professional regulations. It is not a priority sector under OHS legislation, and, since HD is not much affected by changing technology or techniques, the school is not forced to invest in new equipment.

\subsection{OHS in non-traditional contexts}

Six women who were training for non-traditional jobs were interviewed. Four of these women were students, including one in the ASE program. Two were teachers or teachers in training. Some of the findings are presented below and bring out some additional issues related to gender and OHS.

Of interest is the case of the female ASE student (hereafter F). During the group interview, four (out of 10) male students (M) expressed scepticism concerning the capacities of women, in response to a question posed by the researcher (R) about the situation of men and women in non-traditional contexts. They reported, with a certain degree of pride, what they had said to this student and they justified their behaviour by saying that they were helping to prepare her for her future job.

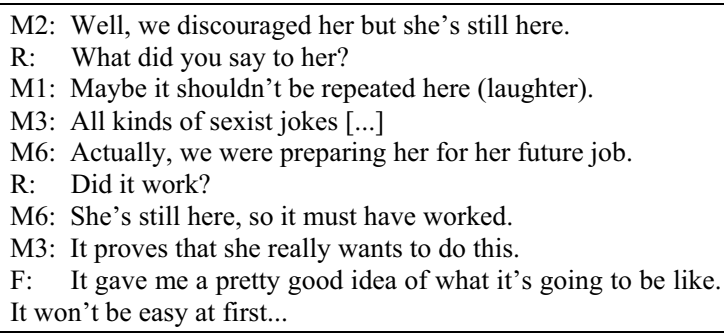

The female student understood that she risked experiencing the same attitudes in the workplace. The teachers tried to control these kinds of situations but they came up nevertheless, revealing the sort of tensions that can affect a person's health and their relation to health $[4,15]$. This tension can also affect some male students who do not subscribe to these discriminatory practices. One male student, who had not spoken up before, sought to distance himself from these attitudes, saying: "It's a woman who showed me how to do my [previous] job." This tension also has an impact, positive or otherwise, on health protection strategies. This fact emerged from the comments of students and a teacher in other programs (fitting and welding and building drawing, refrigeration) who believed that girls take safety more seriously: “ [...] It seems that for guys, it's like: 'Hey, look at me, I can do this, see how good I am?' They'll get on the roof without being secured to a cable. All it takes is one slip and they can fall or even get killed. Since the other guys don't wear a harness, [...] they won't wear one either. If a guy puts one on, he'll look like a pansy [...]." Nonetheless, despite being more aware of safety concerns, female workers end up adopting the low standards of the group so as to be accepted, which makes this issue twice as complex for them [19]. "At school, they make us [follow safety procedures], but when you get to the worksite, you find out that nobody else does, so you don't either. [...] If they're not compulsory [safety glasses], I won't bother."

On the other hand, on the worksite, male workers sometimes recommend that women workers be careful and wear protective gear, even if they don't wear it themselves. This protective attitude reinforces the idea that women are weak and fragile: "The guys at the garage often say to me: "Hey, you're so small, [...] you should wear your safety glasses, [...] or your safely belt, I know no-one else around here wears one but you're so small, you should be careful." The effects of sex-based gender and professional gender [34] thus seem to play out here in relation to OHS among men and women. 


\section{Discussion and conclusion}

This study component helped to identify the representations, practices and effects related to the OHS of students in vocational training centers, and to discuss the particular characteristics of traditionally male and female programs. OHS was found to be influenced by several factors. Some factors are certainly linked to trade-specific characteristics, the constraints associated with them, and relatively important changes at the technological level. Other psychosocial, economic and legislative determinants also emerged. These factors influence the different ways that OHS is approached with regard to female and male students, as well as these students' representation of OHS, their roles, and their health.

As for the Ministry, its approach to OHS is generally the same as that found in many workplaces, that is, OHS is considered in terms of general knowledge and individually applicable rules that are supposed to protect from risks. The psychological dimension of OHS is not developed in ministerial documents except in the form of information on the characteristics of the trade. Despite similarities between the programs, differences can be observed in the way OHS is addressed, which affects the conditions for workshop learning and the way OHS is managed. In hairdressing, OHS is weaker in every respect. It is viewed in terms of individual responsibility and is often confused with rules of hygiene or rules aimed at protecting the safety of clients. Some of the equipment and facilities raised concerns. No record was kept of HD students' injuries or pain, even though several students reported musculoskeletal disorders similar to those of the teachers who had been practising their trade for many years [6], and this worried the students. These situations reflect the fact that women workers have little leverage in this non-unionized sector which is not given priority under the health and safety act.

The electromechanics workshops also presented risks but accidents were recorded and managed to a greater extent. The students were concerned about the gap between conditions at the school and those in workplaces, where prevention is often less developed. However, these students appeared to be aware that firms have a role to play in OHS. On the other hand, the culture in male environments could limit the transfer of learning, as attested by the participating women in non-traditional environments. Psychosocial risks existed in the school (sexual harassment) and are also present in workplaces.
These findings underline the paradox whereby women workers express more concern about OHS but do not comply with the rules so as to be accepted by the "gang" which consists mainly of men who convey a male chauvinist culture of OHS. A double gender issue is at play here: professional gender [34] already comes into play among men in these environments and also affects women; sex-based gender influences the relations between men and women and their representations of OHS. Women in non-traditional trades must give up self-preservation strategies in order to integrate into a male world.

Courses of intervention and research avenues are being explored with the social partners in the fields of education and OHS. All the findings have shown the importance of deconstructing the idea that work in the female-dominated sectors is less risky, that the effects on health in these sectors are not worth reporting, and that OHS risks must be endured. It is also important to deconstruct the idea that complying with OHS rules is a sign of weakness or a lack of virility. This idea causes students, both female and male, to comply less with rules and to take fewer actions on their environments, thus making them more vulnerable to injuries. Moreover, it is necessary to develop approaches to OHS in the ministerial documents and with teachers and school administrators. An important challenge involves supporting the development of know-how on risk avoidance, linked with the tasks and real contexts of a particular trade. The relationship between the results of this component and those of the other components of this research will be explored. This research also focuses on the representations and practices of teachers and other OHS protagonists in the training center. More in-depth studies are needed to document the situation in other programs.

\section{Acknowledgments}

My thanks go to: participants of the Training Center ; Priscille Hastey, Sophie Lévesque, Vanessa Couture, Catherine Delgoulet and Dominique CauBareille for their analysis or advice; and the granting agencies: Fonds québécois de recherche sur la société et la culture, Institut de recherche Robert Sauvé en santé et en sécurité du travail, Services aux collectivités de l'Université du Québec à Montréal, Centrale des syndicats du Québec. 


\section{References}

[1] A.M. Seifert and K. Messing, Understanding women's work: steps toward transformation-An introduction, New Solutions A Journal of Occupational and Environmental Health Policy 17(1-2) (2007), 53-56.

[2] Commission de la santé et de la sécurité au travail, Formation professionnelle et technique, Mieux intégrer les compétences en santé et en sécurité au travail: une mission prioritaire! Ministère de l'Éducation, du Loisir et du Sport, Québec, 2005.

[3] C. Chatigny, A. Balleux, M. Martin and J. Grenier, Apprentissage des tâches et prévention des troubles musculosquelettiques, Recherches et études, IRSST, 2005.

[4] C. Chatigny and C. Gingras, Analyse ergonomique de la situation rencontrée par des femmes en contexte d'emploi traditionnellement masculin, 3rd ICOH International Conference on Psychosocial Factors at Work, Québec City, September 1-4, 2008.

[5] C. Chatigny, K. Messing, E. Laperrière and M-C Thibault, Battle fatigue: Identifying stressors that affect counsellors in women's shelters, Canadian Woman Studies 24(1) (2005), 139-144.

[6] C. Chatigny, P. Hastey, J. Riel and L. Nadon, Le travail enseignant en centre de formation professionnelle et la santé et sécurité : plusieurs enjeux interreliés, Paper presented at the Colloque Le travail enseignant au XXIe siècle, Lyon, 2011.

[7] C. Teiger, Représentations du travail, travail de la représentation, in: Représentations pour l'action, A. WeillFassina, P. Rabardel et D. Dubois, eds., Octarès, Toulouse, 1993, pp. 311-344.

[8] C. Teiger, C. and C. Bernier, Ergonomic analysis of work activity of data entry clerks in the computerized service sector can reveal unrecognized skills, Women and Health 18(3) (1992), 67-78.

[9] E. Ledoux and M. Laberge, Bilan et perspectives de recherche sur la SST des jeunes travailleurs, Recherches et études, IRSST, 2006.

[10] F. Guérin, A. Laville, F. Daniellou, J. Durafourg, and A. Kerguelen, Comprendre le travail pour le transformer: la pratique de l'ergonomie, Agence Nationale pour l'Amélioration des Conditions de Travail, 2006.

[11] Gouvernement du Québec, Rapport interministériel sur le harcèlement psychologique au travail, (2001), http://www.er.uqam.ca/nobel/r33450/jur7141/comite hpsy 7141.pdf, [Online].

[12] Gouvernement du Québec, La formation professionnelle et technique au Québec - Un aperçu, Québec, 2008.

[13] J. Courville, L. Dumais and N. Vézina, Conditions de travail de femmes et d'hommes sur une chaîne de découpe de volaille et développement d'atteintes musculo-squelettiques. Travail et Santé 10 (3) (1994), 17-23.

[14] J. Prévost and K. Messing, Stratégies de conciliation d'un horaire de travail variable avec des responsabilités familiales, Le Travail humain 64 (2001), 119-143.

[15] J. Riel and K. Messing, Counting the minutes: Administrative control of work schedule and time management of secondary school teachers in Quebec, Work, in press.

[16] K. Messing, La pertinence de tenir compte du sexe des opérateurs dans les études ergonomiques: bilan de recherches, Perspectives interdisciplinaires sur le travail et la santé, PISTES 1 (1) (1999), www.pistes.uqam.ca/v1n1/pdf/v1n1a5.pdf, [Online].
[17] K. Messing, C. Chatigny and J. Courville, 'Light' and 'heavy' work in the housekeeping service of a hospital, Applied Ergonomics 29 (6) (1998), 451-459.

[18] K. Messing and C. Chatigny, Travail et genre, in: Traité d'ergonomie, P. Falzon, ed., Presses Universitaires de France, Paris, 2004, pp. 301-316.

[19] L. Pratte, L'accompagnement de l'élève féminine en stage de formation professionnelle dans un métier traditionnellement masculin, Master's Dissertation, Université de Sherbrooke, 2008.

[20] Ministère de l'éducation, Coiffeuses et coiffeurs, coiffeusesstylistes et coiffeurs-stylistes, Analyse de situation de travail, Québec, 1999

[21] Ministère de l'éducation, Électromécanique de systèmes automatisés, Analyse de situation de travail, Québec, 2000.

[22] Ministère de l'éducation, Coiffure, Programme d'études, Québec, 2001.

[23] Ministère de l'éducation, Électromécanique de systèmes automatisés, Programme d'études, Québec, 2004.

[24] M. Laberge, Accueil et intégration sécuritaire et compétence en emploi des élèves inscrits à la formation menant à un métier semi-spécialisé du parcours de formation axée sur l'emploi, Ph.D. Thesis, Université du Québec à Montréal, in press.

[25] M. St-Vincent, N. Vézina, M. Bellemare, D. Denys, E. Ledoux and D. Imbeau, L'intervention en ergonomie, Ouvrage de référence Intervention-ERGO, IRSST, 2011.

[26] M.A. McDiarmid and P.W Gucer, The "GRAS" status of women's work, Journal of Occupational and Environmental Medicine 43(8) (2001), 665-669.

[27] N. Frigul and A. Thébaud-Mony, Où mène le Bac pro?, L'Harmattan, Paris, 2010.

[28] N. Vézina, S. Stock, Y. St-Jacques, L'intensification du travail de couturière: savoir-faire et prévention des douleurs articulaires, in: Organisation et intensité du travail, $\mathrm{P}$. Askenazy, D. Cartron, F. de Coninck, M. Gollac, eds., Octarès, Toulouse, 2006, pp.281-289.

[29] P. Paillé and A. Mucchielli, L'analyse qualitative en sciences humaines et sociales, Armand Colin, Paris, 2003.

[30] R. Ouellette, Statistique de l'éducation: enseignement primaire, secondaire, collégial et universitaire, Ministère de l'Éducation, du Loisir et du Sport, Québec, 2008.

[31] S. Ouellet, Acquisition d'habiletés motrices à la découpe de viande et prévention des troubles musculo-squelettiques: apport de l'analyse ergonomique à la conception de formations, Ph.D. Thesis, Université du Québec à Montréal, 2009.

[32] S. Ouellet and N. Vézina, Du formateur au contenu de formation, Proceedings of the 36th Annual Conference of the Association of Canadian Ergonomists, Halifax, 2005.

[33] S. A. Girard, P. Doyon, L. Gilbert, M. Legris and D. Laliberté, Santé et sécurité du travail et formation professionnelle: Prochaine cible d'intérêt, PISTES 8 (2) (2006), www.pistes.uqam.ca/v8n2/articles/v8n2a1.htm, [Online].

[34] Y. Clot, D. Faïta, G. Fernandez and L. Scheller, Entretiens en autoconfrontation croisée : une méthode en clinique de l'activité, Perspectives interdisciplinaires sur le travail et la santé, PISTES 2 (1) (2000), www.pistes.uqam.ca/v2n1/pdf/v2n1a3.pdf, [Online]. 